九州大学学術情報リポジトリ

Kyushu University Institutional Repository

\title{
The Genus Diostracus Loew from Korea (Diptera, Dolichopodidae)
}

Saigusa, Toyohe i

Masunaga, Kazuhiro

Lee, Chang Eon

https://doi.org/10.5109/2614

出版情報: ESAKIA. 37, pp. 135-140，1997-09-30. Entomological Laboratory，Faculty of Agriculture, Kyushu University バージョン :

権利関係 : 


\title{
The Genus Dostraas Loew from Korea (Diptera, Dolichopodidae) ${ }^{1), 2 \text { ) }}$
}

\author{
Toyohei Saigusa, Kazuhiro Masunaga \\ Biosystematics Laboratory, Graduate School of Social and Cultural Studies. \\ Kyushu University, Fukuoka 8 10, Japan \\ and
}

Chang Eon LeE

615-2, Hyo Mok 2 Dong, Dong Gu, Taegu 701-032. Korea

\begin{abstract}
The genus Diostracus of the family Dolichopodidae is first recorded from Korea. Diostrucus morimotoi sp. nov. is distinctive in having additional setulae on scutellum, and extensively yellow legs and it is described from southern part of the Korean Peninsula. Diostracus maculatus Negrobov, 1980, described from the Primorsky Territory is here recorded from many localities in southern Korea.

Key words: Taxonomy, Diptera, Dolichopodidae, Diostracus, Korea. new species.
\end{abstract}

\section{Introduction}

The hydrophorine genus Diostracus Loew, 1861, includes dolichopodids living on wet rocks and stones in mountain streams. Although it is widely distributed in the northern hemisphere from Europe to North America through Eastern Asia. it prospers extremely in temperate Eastern Asia, where 62 out of 66 named species are distributed. This genus is known from Europe, the best-surveyed region for dolichopodid fauna. only by Diostrucus Zeucostomus (Loew) from Alps, and from N. America by three species. Numbers of species in each region in Eastern Asia are as follows: Far East Russia (5). Japan (12), Taiwan (3), China (1), Burma (4), Nepal (37+1 unnamed). In addition, Saigusa has collected several species of the genus in Yunnan and Guizhou in China. Although no species of the genus hitherto has been recorded from Korea, it is easily expected that the genus occurs in the Korean Peninsula, as it was known from northern Kyushu and Slavyanka, near northeastern border of the Korean Peninsula.

1) Results from the Korea-Japan Co-operative Science Program on "The Evolution and Biogeography of the Insects in the East Asia". No. 25.

2) Contribution from the Biosystematics Laboratory, Graduate Scool of Social and Cultural Studies, Kyushu University (No. 22). 
During surveys of insect fauna in Korea held by Japan-Korea co-operative researches, one of us, Saigusa, has collected a good series of the genus Diostracus at many localities in southern part of the Korean Peninsula. The specimens are mostly represented by a known species, D. maculatus Negrobov, 1980, known from southern Primorsky Territory, but contains only one specimen of a small-sized species which is apparently unnamed and described in the following lines. D. maculatus was described on the basis of 2 males and 4 females from Vladivostok and Slavyanka. As this species was described without illustrations of any morphological characters, the illustrations of wing and male genitalia are given in this paper.

Before going further, we express our sincere thanks to Professor Emeritus K. Morimoto, the leader of the survey. The second author thanks to Prof. H. Shima, Assoc. Prof. 0. Yata, Assist. Prof. B. J. Sinclair, the Graduate School of Social and Cultural Studies, Kyushu University, for their kind guidance. We also thanks to Mr. K. Yoshizawa for his kind help in preparing this manuscript.

Diostracus morimotoi Saigusa et Masunaga, sp. nov.

(Figs. 1, 3)

Diagnosis. Small-sized, generalized species characterized in male by simple and yellow legs with slightly darkened cx3, yellowish white oval palpi, 6 pairs of dorsocentral bristles, 5 short setulae on scutellum besides a pair of scutellar bristles. and short, simple, apically pointed cerci.

Description. Male. Head moderately large, 0.57 times as long as thorax: face and clypeus polished green, with a thin whitish pollinosity laterally: frons green. thinly

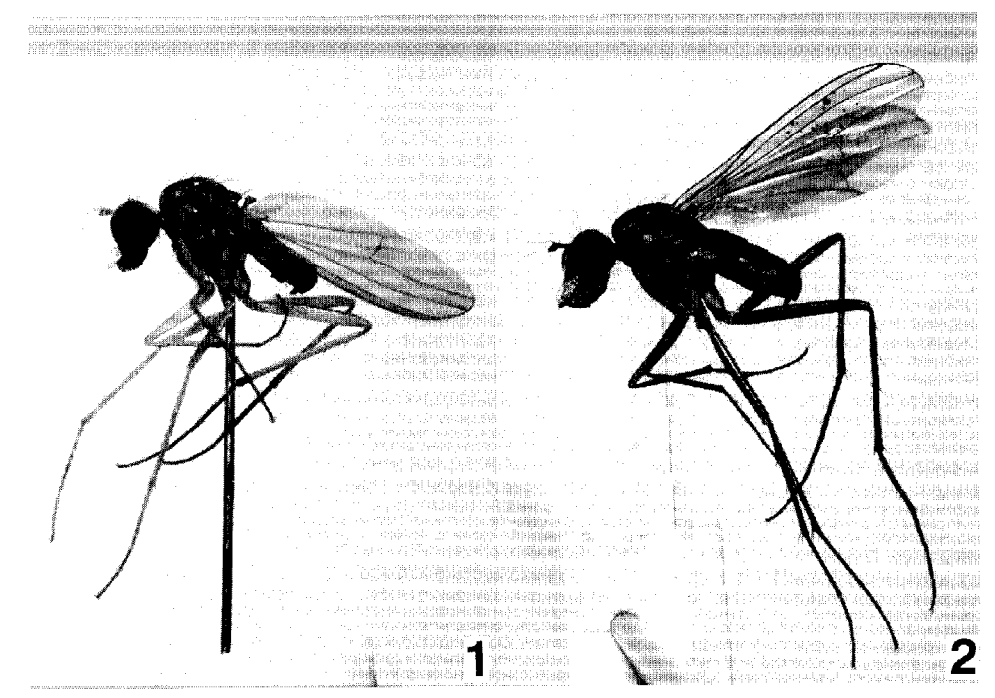

Figs. 1-2. 1, Diostracus morimotoi Saigusa et Masunaga, sp. nov., holotype; 2, Diostrucus maculatus Negrobov, male. 


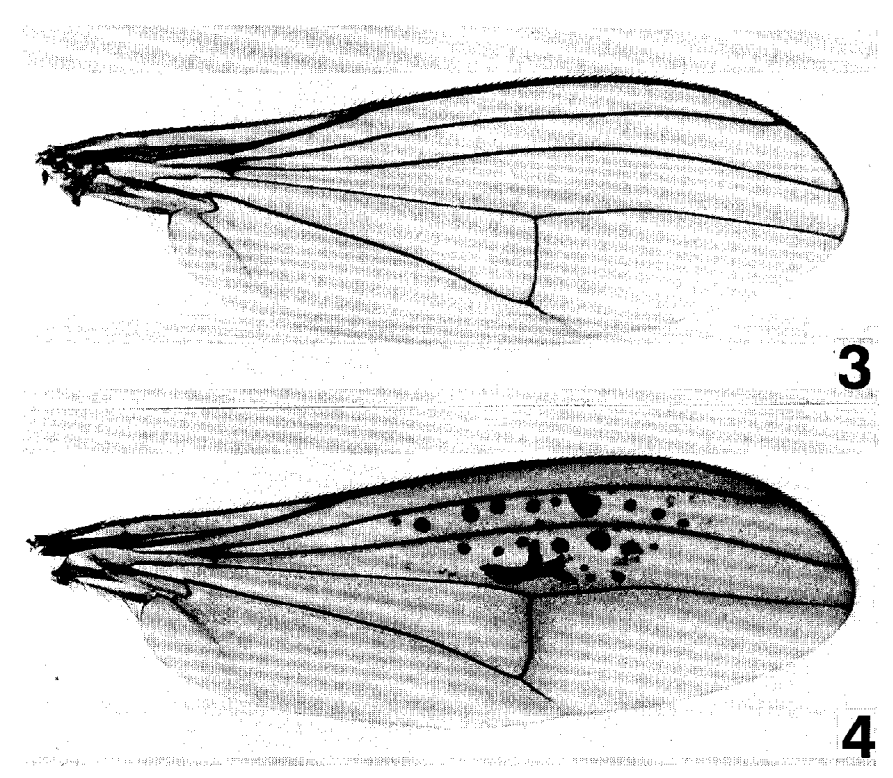

Figs. 3-4. 3, Diostracus morimotoi Saigusa et Masunaga, sp. nov.. holotype., wing; 4, Diostracus maculatus Negrobov, male, wing.

greyish pollinose; occiput dark green, densely greyish brown pollinose; face narrowest at the middle, there it is 0.12 times as long as head. Vertical bristle short, 0.16 times as long as strong ocellar bristles, and less than 1/2 length of postvertical bristles; postocular ciliation black, longer ventrally; occiput clothed with few brownish setae including 1-2 long ones on its ventral half. Antenna short, yellowish brown, 2nd and 3rd segments darker above; combined length of 3 antennal segments equal to 0.4 times length of head: 1st segment long, 1.5 times as long as its apical thickness, 2nd segment globular, 2/3 as long as 1st, with a short black setulae; 3rd segment 1.6 times as long as 2 nd, slightly longer than thick, nearly triangular in shape, tapered beyond the middle: arista dorsal, arising from the middle of dorsal margin of 3rd segment, simple, short pilose throughout its length. Palpus oval, slightly shorter than 2 times its width, yellowish white, covered with whitish silvery pruinosity and sparsely with short, fine, pale hairs which are not prominent. Probosicis moderately large, with a few longish setae along distal margin.

Thorax green, but darkened to bronze along lateral margins of mesonotum; polished on mesoscutum, dark brown pollinose on sides of scutum and scutellum; otherwise fairly densely greyish pollinose; mesoscutum more or less cupreous discally, with a pair of narrow dark subdorsal stripes extending to in front of prescutellar portion. Chaetotaxy: Six long dorsocentral bristles; the 3rd dorsocentral 1.3 times as long as scutellum; the 6th the longest; 1 humeral with 2 minute setulae, 1 posthumeral, 1 long anterior and 1 shorter posterior notopleurals, 1 strong supra-alar, 1 strong postalar as long as the 6th dorsocentral; a short sutural and a similar postsutural setae; scutellum with 5 black short marginal setulae in addition to a pair of strong scutellar bristles; proepisternum with a black seta and 2 minute white hairs at least on left episternum; otherwise pleura free from 
Table 1. Relative lengths of leg segments of D.morimotoi, male.

\begin{tabular}{l|c|c|c|c|c|c|c}
\hline & \multirow{2}{*}{ Femur } & \multirow{2}{*}{ Tibia } & \multicolumn{5}{|c}{ Tarsus } \\
\cline { 4 - 8 } & & & 1 & 2 & 3 & 4 & 5 \\
\hline Fore leg & 100 & 104 & 52 & 30 & 24 & 16 & 15 \\
Middle leg & 129 & 152 & 81 & 35 & 25 & 1.5 & 15 \\
Hind leg & 157 & 181 & 77 & 45 & 31 & 20 & 16 \\
\hline
\end{tabular}

setae.

Legs yellow, cx2 and cx3 dark yellowish brown, darkened proximally with a greenish tinge, and greyish pollinose; extreme tip of $\mathrm{t} 3$, 2nd to 5th tarsomeres of tarl and tar2 blackish brown. Legs slender and simple, with no modification or special vestiture. Relative lengths of podites as in Table 1. Coxae simple, cx 1 clothed in front with fine black hairs, which are longer towards base, and mixing a long subbasal bristle, and with a row of black setae along anterodistal margin; cx 2 clothed with black setae in front, and apical ciliation of black setae longer towards inner anterior corner; cx 3 with a few setae laterally and on anterior margin towards tip. Femora only short setose, bearing very short, fine, pale hairs on ventral surface; f3 with a long anterior subapical bristle; all femora with a short posterior subapical bristle. Tibiae slender and simple, short setose: $\mathrm{t} 1$ with 2 anterodorsal, 1 posterodorsal and 1 posteroventral short bristles; t 2 with 3 long anterodorsal, 2 short posterodorsal bristles, and apical bristles; t3 with 4 strong anterodorsal, 2 short posterdorsal bristles (one subbasal, another beyond the middle), and apical bristles, some anteroventral and posteroventral setae prominent towards tip of $\mathrm{t} 3$. Tarsi slender and short setose, without special modifications. Unguis. empodium and pulvillus of normal condition for the genus Diostrucus.

Wing moderately narrow, 3 times as long as wide, evenly tinged with brownish grey. with brown veins; no specialization on wing shape, markings and venation; $\mathrm{R}_{4+5}$ more strongly sinuate than $\mathrm{R}_{2+3}$, weakly diverging from the latter on its apical $1 / 3$; discal crossvein situated at 0.6 of wing; discal crossvein almost straight, slightly arched outwards at the posterior half, anterodistal corner of discal cell slightly obtuse, posterodistal corner almost rectangular. Halter yellowish brown, darker on knob.

Abdomen short, 1.2 times as long as thorax, dark brown, with a slight greenish tinge on terga laterally; terga rather densely greyish pollinose, more thinly along posterior margin of each tergum; terga only short black setose; posterior ciliation of tergum differentiated and strong only on 1st tergum. Genitalia small and simple; cercus small. $1 / 3$ as long as depth of genital capsule, tapered beyond the middle to pointed tip. short pilose, with a few long hairs at tip; no specialization or special vestiture recognizable externally.

Length: Body $3.4 \mathrm{~mm}$; wing $4.5 \mathrm{~mm}$.

Holotype male, Samgak-Koji, 1000-1300m, Macheon-Myeon, [Korea], 14. vii 1991. T. Saigusa [leg]. (donated to the collection of Biological Laboratory, Kyongpok University by the collector).

Remarks. The male of this species is distinguishable from the named species of this genus by its small size, complete notal chaetotaxy with additional setulae on the scutellum, extensively yellow legs, and large, oval, silky yellowish white palpi. In a key 
to species by Takagi (1972), this new species runs to Diostracus flcwipes Takagi. 1968 from Japan, which differs from the new species in having the strong vertical bristles. long yellow hairs on ventral surface of occiput, shorter and more yellowish palpi, no additional scutellar setulae, and acute posterodistal corner of the wings. In a key to Nepalese species by Saigusa (1984), the new species runs to Distracusumbrinervis Saigusa, 1984, and Diostracus tangalensis Saigusa, 1984, which have black legs, and ornamentations (in D. tangalensis) or specialized vestiture (in D. tumbrinervis). This species is named after Dr. Katsura Morimoto, the leader of our insect faunal survey in Korea.

Diostracus maculatus Negrobov, 1980

(Figs. 2, 4, 5)

Diostracus maculatus Negrobov, 1980. Vest. Zool. , Kiev, 1980(4):18- 19.

The following specimens were collected by Saigusa in Korea. Judging from the collecting data, this species is widely spread in southern part of Korean Peninsula. It occurs in lowland (400 $\mathrm{m}$ in Naeryeong-Ri) to mountain region $(1000-1300 \mathrm{~m}$ in Samgak-Koji) even in the southernmost part of the Peninsula. This species occurs in mountain streams of various sizes, and sometimes even at small cascades and seepages.

Specimens examined: 7 males 7 females, Kwangneung, Soheul-Myeon, KyeonggiDo, 16. July 1992, T. Saigusa col.; 3 males 2 females, Bongmyong-Ri. Tongsan-
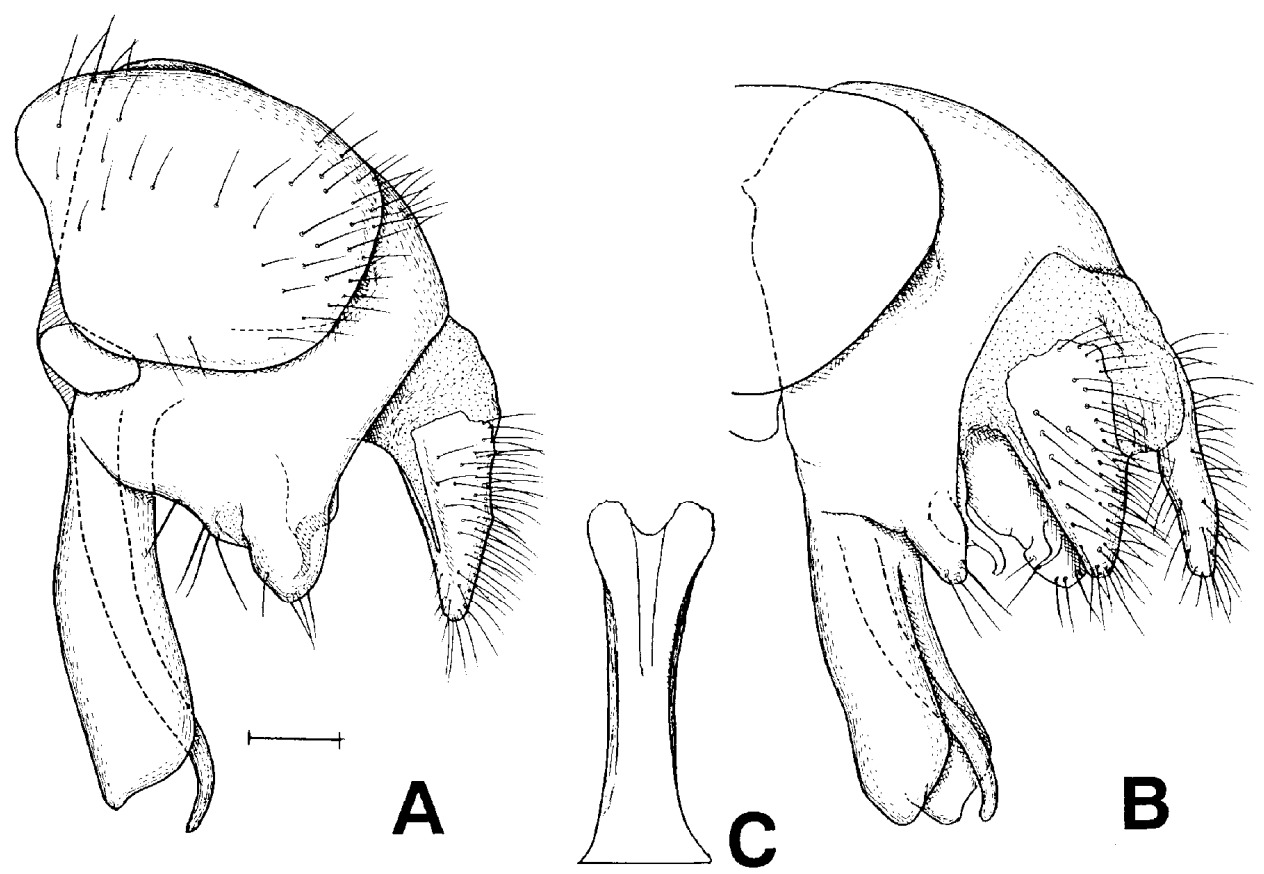

Fig. 5. Diostracus maculatus Negrobov, male genitalia. A: Lateral aspect. B: Posterolateral aspect. C: Ventral process, ventral aspect. 
Myeon, Kangweon-Do, 21. July 1992, T. Saigusa col.; 1 male 1 female, Samgak-Koji, 1000-1300m, Macheon-Myeon, Kyongsangnam-Do, 6. June 1991, T. Saigusa col.; 5 males 1 female, same locality, 14. July 1991, T. Saigusa col.; 1 female, Samjeong, 600$800 \mathrm{~m}$, Hwangae-Myeon, Kyongsangnam-Do, 8. June 1991, T. Saigua col.; 1 male 4 femals, Manbokdae, 1000-1200m, Sannae-Myeon, Chollabuk-Do, 5. June 199 1, T. Saigusa col.; 1 female, Naeryeong-Ri, 400m, Sannae-Myeon, Chollabuk-Do, 7. June 1991, T. Saigusa col.

\section{References}

Negrobov, 0. P., 1973. Genera and subgenera of the subfamily Hydrophorinae (Diptera. Dolichopodidae) of Holoarctic. Zool.Zh., 52: 1514-1520. (in Russian)

Negrobov, 0. P., 1978. 29. Dolichopodidae. In Lindner, E. (ed.) "Die Fliegen der palaearctischen Region", 4(5): 387-418.

Negrobov, 0. P., 1980. New data for the study of species of the genus Diostracus Lw. (Diptera, Dolichopodidae). Vest. Zoo., Kiev, 1980: 16-20. (in Russian)

Negrobov, 0. P., 1991. Dolichopodidae. In Soos, A. \& L. Papp (ed.) "Catalogue of Palaearctic Diptera", 7: 11-139, Akadémiai Kiado, Budapest.

Saigusa, T., 1984. The genus Diostracus from Nepal (Diptera, Dolichopodidae). Bull. Kitakyushu Mus. Nut. Hist., 5: l-74.

Saigusa, T., 1995. New species of the genus Diostracus from Eastern Asia (Insecta. Diptera, Dolichopodidae). Bull. Graduate School Social Cultural Studies, Kyushu Univ., 1: 73-85.

Takagi, S., 1968. The Dipterous genus Diostracus (Dolichopodidae). Ins. Matsum.. 31: 35-62.

Takagi, S., 1972. Four new species of Diostracus Loew from Nepal (Diptera. Dolichopodidae). J. nut. Hist., 6: 521-546. 